\title{
关于工程全过程造价咨询控制要点分析
}

谢琼

青海创金工程咨询股份有限公司

DOI:10.32629/btr.v1i6.1676

[摘 要] 改革开放以来,我国经济建设发展迅速。与此同时,许多项目在各地蓬勃发展。相关的工程建设管理体系逐步完善。 在项目建设过程中, 项目成本管理的作用日益突出。项目成本咨询逐渐从单一环节变为整个过程。在一定程度上,项目整个过 程成本的质量直接影响到项目各个方面的建设成本。本文阐述全过程成本咨询中存在的一系列问题的基础上,提出了成本控 制咨询在整个工程过程中的关键点, 从而有效地提高了成本控制的质量项目进程,促进工程经济效益的进一步增长。

[关键词]工程；造价咨询；意义；控制要点

国民经济建设快速发展的阶段, 各行业发展迅速, 行业 竞争也十分激烈。如果想要在大环境中生存, 必须正确管理 它。在进行建设项目成本管理工作时, 由于这些因素, 建设项 目的实际成本往往大于预算。这不仅影响了项目的进度和整 体质量, 而且阻碍了实现最大的经济效益。因此, 作为建设项 目成本控制工作者, 必须把握建设项目成本控制工作的重点, 探索超出实际情况的建设项目成本预算的原因, 还要制定有 效的方案, 严格控制建设项目成本预算。

\section{1 整个过程造价咨询的意义}

通过提供全过程成本咨询服务, 员工不仅可以满足业主 的成本控制需求, 还可以帮助业主提高资金使用效率, 保证资 金使用的合法性和合理性。此外, 通过全过程成本咨询, 业主 还可以帮助业主合理优化设计方案, 并使用配额设计来满足 项目成本控制要求, 确保工程设计符合经济和可行性要求, 并 且业主单位的好处。促销活动奠定了良好的基础。

\section{2 项目工程造价存在的问题}

首先, 我国的建设项目投资上 “三超” 的现象较为普遍。 结算超预算、概算超估算、预算超概算这三种现象并没有得 到建设单位的足够重视。很多建设单位会认为提升了项目的 档次和使用功能, 在造价上提升点也无大碍, 但是这样的 “觉 悟” 往往滋生了腐败, 也使得国有资金不断流失。国家的确 在建设项目的审计力度方面进行了加强, 各建设单位也认识 到了这些问题的严重性, 都尽量地区避免 “三超” 发生。

其次, 我国的工程造价控制体系形成较晚。由于成形较晚, 就造成了全过程造价控制理念和系统性的缺乏。参与工程造 价管理的人员文化素质参差不齐, 文化水平高低不齐。因此, 想要提升整体的水平是较为困难的, 这就对工程造价的控制 水平有了一定的提高限制。很多投资者都是将精力放在建设 项目的实施阶段, 而不去注重决策阶段, 哪怕施工阶段的控制 做得再完善, 也是无法弥补决策的失误所带来的巨大经济损 失。同时, 竣工决算和项目后评价也是被建设单位所忽视的, 但是其实这个阶段的经验累积对于以后的项目实施是能提供 很好的借鉴和经验补充的。

再次, 我国实行建设项目的管理中, 存在着一些错误的观
念, “重技术轻造价”。很多人都认为, 只要整个项目能够安全 的完成, 造价上面花多点无所谓。这样的观点是十分错误的, 因为建设的质量、进度以及造价这三大因素其实是息息相关 的, 这三者是相互影响且相互制约的。我们在造价管理研究中, 只是提升了技术的水平, 不够重视节约项目上的投资的话, 是 一种失衡现象。建设项目如果 “重技术轻造价”, 认为建设质 量过了就不需要节约造价的话, 是根本无法形成一个完善合 理的造价控制体系的。应该结合双方，进行统一控制。

\section{3 浅析工程项目全过程造价咨询控制要点}

3.1 投资决策阶段的工程造价控制分析

投资决策阶段的成本控制是一个特别重要的部分和基 本部分。为确保项目建设的顺利实施, 成本顾问和施工单位 需要在项目建设前做相应的调查工作。在此基础上, 进行了 项目计划设计, 并结合计划制定了项目投资计划。(1)对于成 本咨询机构而言, 在投资决策阶段, 关键任务是预算项目建 设全过程所需的投资。值得注意的是, 预算需要深入到施工 现场, 分析工程建设功能, 以确保预算的合理性, 并在一定程 度上确保为后续施工提供足够的资金。(2) 设计阶段的施工 成本控制。在这个阶段, 项目成本咨询的主要任务是分解项 目并估算每个环节项目的成本。值得注意的是, 在估算过程 中, 有必要确保设计的技术合理性和经济合理性。核心是根 据项目的质量要求尽可能减少投资。(3) 招标阶段的项目成 本控制。在招标阶段, 有必要积极实施相关的成本控制工作。 原因是招标质量直接关系到建筑工程材料, 施工队伍和监理 团队的质量。在这个阶段, 我们需要关注以下几点。首先, 要做好材料质量, 技术水平和设备的监控工作, 避免因具体 施工过程中的材料质量和机械设备对施工质量的影响。因此, 在选择材料供应商时, 有必要全面考虑供应商的能力, 包括 供应商资格, 供应材料的质量和材料供应能力。值得注意的 是, 在材料选择上, 还必须全面考虑材料质量, 不要盲目追求 低价, 忽视材料质量问题。只有在保证建筑材料质量的基础 上, 才能保证施工进度顺利进行。二是加强对监管人员和监 管公司业务能力的分析。在具体的施工过程中, 监督对质量 的影响更大。 


\section{Building technology research 建堎技术研究}

第 1 卷 第 6 期 版本 1.0 2018 年 special issue 文章类型：论文|刊号 (ISSN): 2630-4651

\section{2 严格审查施工准备工作}

工作人员应注意审查土木工程施工现场的施工准备工 作, 确定是否能满足业主的进度要求, 确定主要施工环节是 否到位, 确定是否交叉运行部门程序合理, 确定施工劳动组 织和机械。设备配置是否能满足实际施工需要, 确定施工组 织设计方案是否符合分项编制的要求, 确定关键技术方案是 否在关键施工环节制定, 确定施工机械是否和设备准确准备, 具体设备型号和数量是否规划工作时间等方面都能满足施 工方案的需要。

\section{3 严格审查设计变更}

鉴于设计过程对项目成本控制的重要影响, 员工应对设 计变更进行严格审查, 以实现对设计变更的有效控制。目前, 项目的大部分施工单位都是通过招标选出的, 有的施工单位 在招标过程中故意降价, 并以低价获得施工资质。当混凝土 结构用于保护建筑效益时, 将进行设计变更。增加项目成本。 因此, 工作人员应将设计变更作为施工阶段成本咨询控制的 重点, 帮助业主审查设计变更, 确保设计变更的合理性和标 准化。此外, 施工期紧张, 任务繁重。因此, 施工单位往往急 于施工, 没有足够的时间投入到工程设计中, 使得工程设计 难以满足实际需要和缺乏可行性。这样, 在实际施工过程中, 会发生设计变更, 确保项目施工效果能够满足相关要求。

\section{4 施工过程的项目成本控制}

该项目最关键的部分是项目的具体实施。因此, 搞好施 工阶段的施工成本是非常重要的。这部分成本占项目总成本 的 $70 \%$ 以上。从这一点来看, 我们可以很容易地看到, 为了 优化项目成本的管理, 我们必须选择从项目实施中进入。上 面提到企业是为了自己的经济利益, 最大化经济效益的关键 在于此。因此, 在这个阶段, 我们不仅要确保施工设计的合理 性, 还要特别注意图纸的设计。不仅如此, 但可能会有一系列 需要对图纸进行一些更改的更改, 我们还需要确保更改。后 续图纸符合施工要求; 除施工图纸的技术控制外, 应严格控 制变更成本, 防止资金在变更后超出预算; 最后要说的是改 进相关系统, 包括合同管理系统。以及改变资金的控制系统。

3.5 完成阶段的项目成本控制
作为项目的结束, 完工结算也是对项目建设的最终结果 的检查。它是项目质量, 质量检验的最后一道证书以及项目成 本控制的最后一个检查点的保证。提高项目成本最重要的是 能够审查投资使用的合理性并审查项目的质量。因此, 这一阶 段的结束是一项审计工作。尽管工作量很小, 但他的重要性是 不容置疑的。不同的是, 制定了不同的审计制度, 客观评价了 项目完成率, 给出了审计报告, 有关部门有数据进行分析, 审 查了原材料的利用率和利用率, 制定了具体的成本清单。

\section{6 提高项目成本管理人员的整体素质}

建设项目成本控制工作具有很强的专业性和复杂性。因 此, 提高建设项目成本控制工作水平的前提是提高相关人员 的工作能力。一是加强对相关工人职业能力的培养, 使每位 员工精通各种成本控制理论知识。第二是将工程设计, 施工 技术和原材料采购知识作为培训内容的一部分。三是建立严 格的奖惩机制, 鼓励员工在成本控制工作中保持高度的积极 性, 这也有利于提高成本控制工作的质量。

\section{4 结束语}

建设工程全过程的成本管理咨询相关法律制度有待完 善。尚未形成有效的全过程成本管理咨询服务体系。整个过 程成本管理咨询方的约束和监督是不够的, 但工程量清单定 价模型的有力推广必将促进整个过程成本管理咨询业务的发 展。相关政府部门或行业协会应鼓励和规范全过程成本咨询 服务市场的建设, 为成本咨询机构提供参与项目定价基础编 制, 发布成本信息, 提供区域计量建议的平台。或集团价格原 则。充分发挥他们作为桥梁的作用。作为一种先进的管理模 式, 工程的全过程成本咨询应用于项目的建设, 可以减少一些 不必要的工程造价支出, 有助于进一步提高项目的经济效益。

\section{[参考文献]}

[1]周丽.浅谈工程量清单计价模式下招投标阶段的工 程造价控制[J].成功(教育),2014,(11):69.

[2]杨伏明,单正乐.初探工程量清单计价模式下招投标 阶段的工程造价控制[J].中国招标,2018,(12):38.

[3]李小琳, 各红育. 全过程工程咨询的探索与实践 [J].建 筑市场与招标投标,2018,(06):55-59. 